\title{
Assessment of Clinical Utility of Erythrocyte Glutathione Transferase as Biomarker of Hemodialysis Adequacy in pediatrics
}

A.S.El- Hamshiry, E.R.Abdel-Gwad, R.A.Elsayed,W.A.Abdel-Halim and O.M.Ramadan

Pediatrics Dept., Faculty of Medicine, Benha Univ., Benha, Egypt

E-Mail:Omnia@gmail.com

\begin{abstract}
Recent studies showed that Kt/Vurea in dialysis cannot represent correctly the removal of other solutes and fluid, indicating that this parameter alone should not be used as the sole indicator of dialysis adequacy. We aimed to identify whether Erythrocyte glutathione transferase as biomarker for haemodialysis adequacy in children with End Stage Renal Disease (ESRD) on regular haemodialysis. This study was conducted on 50 persons divided into two groups. Group A: 2 5ESRD patients receiving conventional hemodialysis atBENHA university hospitals hemodialysis units. GroupB(Control): 25 aPP.arently healthy subjects. All patients was subjected to Erythrocyte glutathione transferase with ELISA technique. Our study showed that Erythrocyte glutathione transferase cut off value in HD patients 39,1 ng/dl. its sensitivity was $81 \%$, specificity was $88,9 \%$ and accuracy was $84 \%$.In our study The post HD analysis of E-GST level showed significant difference between control and conventional HD (p- value 0.001\&0.001) respectively. This means that E-GST has the same power to express dialysis adequacy like URR, Kt/V Urea, Also it is mirror of URR \& Kt/V. Erythrocyte glutathione transferase is highly sensitive \& specific marker in hemodialysis patients and its level can express hemodialysis adequacy and toxins removal in several sessions by different hemodialysis modalities.
\end{abstract}

\section{Introduction}

Primary causes of CKD in children significantly differ from those that are responsible for the adult onset of the disease. In fact the main aetiologic factors of CKD in children, steroid-resistant nephrotic syndrome (SRNS), chronic glomerulonephritis (e.g. lupus nephritis, Alport syndrome) and renal ciliopathies [1]

The hemodialysis adequacy and dosing are usually discussed only in terms of $\mathrm{Kt} / \mathrm{Vurea}$, a mathematical model that takes into account the urea clearance in a single hemodialysis session. Recent studies showed that $\mathrm{Kt} /$ Vurea in dialysis cannot represent correctly the removal of other solutes and fluid, indicating that this parameter alone should not be used as the sole indicator of dialysis adequacy. Thus, other dialysis biomarkers have been proposed (i.e,. p-cresol, beta-2-microglobulin, guanidine compounds, high-through put molecular fingerprinting assays), but their quantifications require complex and expensive proceduresand again they only measure the efficiency of a single dialytic session. Thus, the identification of new clinical to reveal the degree of blood purification from small as well as large toxins in a wide range of dialytic sessions will be of medical interest [2].

Glutathione transferase is expressed in some human tissues and is abundant in mammalian erythrocytes (eGST). This enzyme is able to detoxify the cell from endogenous and exogenous toxic compounds by using glutathione (GSH) or by acting as a ligandin [3].

Glutathione-S-transferases represent a superfamily of enzymes involved in cell protection and detoxification, prominent function of these enzymes is the conjugation of GSH to toxic hydrophobic compounds provided by an electrophilic center. This reaction facilitates toxin inactivation and renal elimination. Red blood cells express almost exclusively a single GST isoenzyme, GST-P1which represents more than $95 \%$ of the erythrocyte GST (e-GST) pool.Over-expression of eGST has been found in uremic patients under maintenance hemodialysis(MHD), and e-GST has been proposed as novel biomarker for dialysis adequacy complementary to Kt/Vurea and in subjects affected by hyperbilirubinemia [4].

We aimed to identify whether Erythrocyte glutathione transferase as biomarker for haemodialysis adequacy in children with End Stage Renal Disease (ESRD) on regular haemodialysis.

\section{Patient and method}

This study will be conducted on 50 persons divided into two groups. Group A: 2 5ESRD patients receiving conventional hemodialysis atBENHA university hospitals hemodialysis units. GroupB(Control): 25 aPP.arently healthy subjects.

\subsection{Inclusion Criteria}

- Children< 18 years

- ESRD on regular HD for at least 6 months, receiving 3 sessions /week, each session 4 hours

\subsection{Exclusion Criteria}

- Hyperbilirubinemia

- Chronic liver disease

\section{Patients were subjected to the following}

1. An informed consent

2. History taking \& examination including:Etiology of ESRD, duration of hemodialysis in months, dry weight, dialysis prescription and Iron \& erythropoietin therapy

3. Complete blood count (CBC).

4. Chemistry: AST, ALT, total bilirubin,direct bilirubin Serum creatinine, calcium, phosphorus.

5. PTH.

6. Iron study (serum iron, TIBC, Ferritin)

7. Pre-dialysis urea, post dialysis urea $\& \mathrm{Kt} / \mathrm{V}$ urea and urea reduction ratio (URR) was calculated.

8. Erythrocyte glutathione transferase with ELISA technique. 


\section{All control were subjected to}

1. An informed consent.

2. Serum creatinine, Total \& direct bilirubin.

3. Erythrocyte glutathione transferase with ELISA technique.

\section{Samples collection \&storage}

All samples were obtained by EDTA containing tube after collecting the samples, the serum was allowed to clot for 10-20 minutes at room temperature then Centrifugation was done (at 2000-3000 RPM) for 20 minutes. Then supernatants were collected and stored at $20 \mathrm{C}$.

\section{Results}

Our result shows high statistically significance difference between patients and control as regard F.H OF CRF, Anaemia and hepatitis while there is no statistically significance as regard Age,Sex and Residence

Our result shows high statically significance between haemodyalysis patients with $(\mathrm{KT} / \mathrm{V}<1,3)$ and $(\mathrm{KT} / \mathrm{V}>1,3)$ as regard Creat.1, Creat.2, urea1, urea2, URR, E_GST 1, E_GST 2. Our result shows high statistically significance between pre and post in haemodialysis patients with $(\mathrm{KT} / \mathrm{V}<1,3)$ regard as Creat. ,urea, E_GST.

Our result shows high statstically significance between pre (1),post(2) haemodyalysis group with $(\mathrm{KT} / \mathrm{V}>1.3)$ as regard Creat., urea, E_GST. Our result shows that hemodialysis patients who have elevated E_GST level have higher risk to have inadeqate dialysis more than negative ones.

Our result shows that cut off point to detect inadequate dialysis $(\mathrm{KT} / \mathrm{V}<1,3)$ is $39,1 \mathrm{ng} / \mathrm{ml}$ with $81,3 \%$ sensitivity , $88,9 \%$ specificity and area under curve 0,872 . Our result shows that prevalence of E_GST level in inadequate dialysis group $(\mathrm{KT} / \mathrm{V}<1,3)$ was 64 $\%$ ( 16 patients) while in group receiving adeqate dialysis $(\mathrm{KT} / \mathrm{V}>1,3)$ frequency was $36 \%$ ( 9 patient) $\mathrm{p}$ value 0,002

Our result shows high statsically significance E_GST post in haemodyalysis group as regard TLC, Creat. 2 ,urea2 ,URR ,KT/V.while there is no statistically significance as regard other variables(age,duration of $\mathrm{RF}$,duration of haemodailysis, $\mathrm{Hb}$ ,plt,mcv, $\mathrm{MCH}, \mathrm{Na}, \mathrm{K}, \mathrm{Ca}$ t,Cai,po,PTH,AST,ALT,Bilirubin,D.bilirubin,FE,TIBC,F errtin,HbA1C.

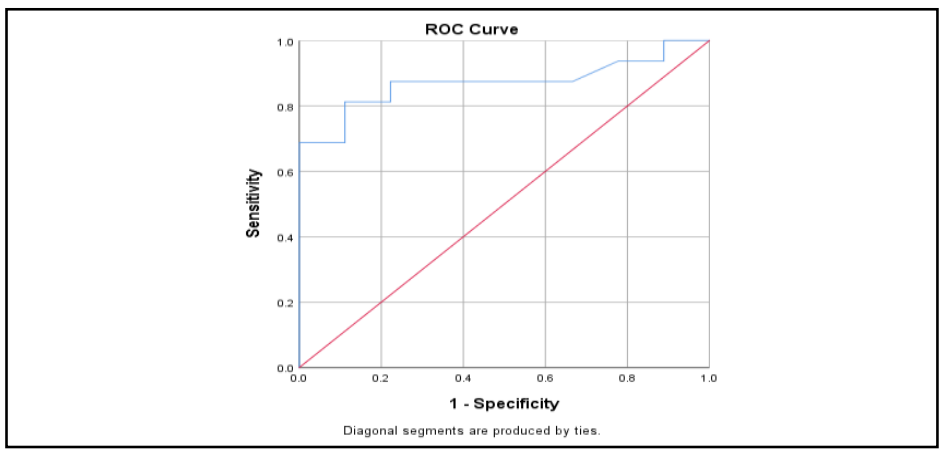

Fig (1) Logistic regression analysis for the association between E-GST and adequate dialysis $(\mathrm{Kt} / \mathrm{V}>1.3)$

Table (1) Validity of E-GST in prediction of low KT/V.

\begin{tabular}{llllllll}
\hline & \multicolumn{2}{l}{ KT/V $\leq \mathbf{1 . 3}(\mathbf{1 6})$} & \multicolumn{2}{l}{ KT/V >1.3 (9) } & Test & P value & Sig \\
& $\mathbf{N}$ & $\mathbf{\%}$ & $\mathbf{N}$ & $\mathbf{\%}$ & value & & \\
\hline E-GST & 13 & 81.3 & 1 & 11.1 & FET & 0.002 & HS \\
$\geq 39.1$ & 3 & 18.7 & 8 & 88.9 & & & \\
$<\mathbf{3 9 . 1}$ & 0.872 & & & & & \\
AUC & 39.1 & & & & & \\
Cut-off point & 81.3 & & & & & \\
Sensitivity & 88.9 & & & & & \\
Specificity & 92.9 & & & & & \\
PP.V & 72.7 & & & & & \\
NPV & 84.0 & & & & & & \\
Accuracy & & & & & & & \\
\hline
\end{tabular}

Table (2) Correlation between E-GST Post regular HD sessitions and other variables.

\begin{tabular}{llll}
\hline Group A (25) & r test & P value & SIG \\
\hline Age(years) & -0.15 & 0.48 & NS \\
Duration of RF & -0.05 & 0.82 & NS \\
Duration of haemodialysis & -0.005 & 0.98 & NS \\
Hb & 0.27 & 0.19 & NS \\
\hline
\end{tabular}




\begin{tabular}{llll}
\hline Table (2) Continue & & & \\
\hline TLC & -0.51 & 0.009 & $\mathrm{HS}$ \\
PLT & -0.09 & 0.67 & $\mathrm{NS}$ \\
MCV & -0.09 & 0.67 & $\mathrm{NS}$ \\
MCH & -0.19 & 0.36 & $\mathrm{NS}$ \\
Na & 0.30 & 0.15 & $\mathrm{NS}$ \\
K & -0.27 & 0.20 & $\mathrm{NS}$ \\
CAT & 0.31 & 0.14 & $\mathrm{NS}$ \\
CAI & 0.26 & 0.21 & $\mathrm{NS}$ \\
PO & -0.06 & 0.76 & $\mathrm{NS}$ \\
AST & 0.11 & 0.61 & $\mathrm{NS}$ \\
ALT & -0.08 & 0.72 & $\mathrm{NS}$ \\
PTH & 0.23 & 0.26 & $\mathrm{NS}$ \\
FE & 0.006 & 0.98 & $\mathrm{NS}$ \\
TIBC & 0.06 & 0.78 & $\mathrm{NS}$ \\
Ferritin & -0.27 & 0.19 & $\mathrm{NS}$ \\
Bilirubin & -0.02 & 0.93 & $\mathrm{NS}$ \\
D. Bilirubin & 0.14 & 0.51 & $\mathrm{NS}$ \\
HbA1c & -0.14 & 0.51 & $\mathrm{NS}$ \\
Creat.2 & 0.27 & 0.19 & $\mathrm{NS}$ \\
Creat.2 & 0.49 & 0.013 & $\mathrm{~S}$ \\
Urea 1 & 0.15 & 0.47 & $\mathrm{NS}$ \\
Urea 2 & 0.58 & 0.003 & $\mathrm{HS}$ \\
URR & -0.72 & $<0.001$ & $\mathrm{HS}$ \\
KT/V & -0.77 & $<0.001$ & $\mathrm{HS}$ \\
\hline
\end{tabular}

\section{Discussion}

Hemodialysis is a life-saving procedure for ESRD patients, the amount of uremic toxins removal has an impact on patients morbidity and mortality so adequate hemodialysis is highly required in order to improve the quality of life [5].

Urea reduction ratio (URR) and $\mathrm{Kt} / \mathrm{V}$ have been used as an index of dialysis adequacy for more than 30 years despite uremic syndrome is more than urea accumulation and different toxic solutes contribute to uremic illness so adequate dialysis should calculate the fractional removal of each single toxin [6].

Erythrocyte glutathione transferase (e-GST) is nondialyzable enzyme compartmentalized in the red cells. It may act as ligandins by binding and sequestering a variety of small or large toxic

compounds and peptides [7]. E-GST may be an innovative tool able to measure the efficiency of multiple dialysis sessions, its expression is linked not only to the quantitative level or size of blood toxins, but to their own specific toxicity, it may be complementary or alternative to the $\mathrm{Kt} / \mathrm{V}$ urea [8].

e-GST represents an efficient probe of long-term and E-GST level can monitor the specific competence of the kidney to sweep many dangerous toxins [9].

In this study we verified whether E-GST is a novel biomarker of hemodialysis adequacy in different dialysis techniques (standard bicarbonate hemodialysis (HD) and (post dilutional OL-HDF) or complementary to the Kt/V urea.

The different in this study is that we assess EGST level not activity as activity was studied before by [4].
This study included 50 patients, 34 males and 26 females divided according to modality into 2 groups matched as regard age and sex.

In our study there were no significant difference between both groups as regard age, sex etiology

This agreed with [4], there was no significant difference between two groups as regard age, sex and etiology of hemodialysis .

In our study the patients on conventional $\mathrm{HD}$ as regard blood pressure that normotensive patients (13) (52\%) hypertension [7] (28\%) patients hypotensive patients (5)(20\%) respectively.

Patients were more normo tensive than hypertensive and they received antihypertensive drugs

This agreed with [4], there was no significant difference between conventional HD as regard hypertension (21) patients (35\%),(17) patients (38\%) respectively p- value $>0.05$.

Our study revealed that the patients on conventional heamodyalysis with hemoglobin level range $(7-16,7 \mathrm{mg})$ (Mean+_SD 10,94+_2,70)

This agreed with [10] showed that in the patients on conventional heamodyalysis there was no significant difference as regard hemoglobin level.

In our study the patients on conventional HD had significant changes on parathyroid hormone level ( Mean +_ SD ) (270+_193)

In our study the E-GST level in patients on regular $\mathrm{HD}$ and control group were (Mean $\pm \mathrm{SD}$ $51,69+88,24 \mathrm{ng} / \mathrm{dl}$ )and (Mean+_SD $\left.7,40+\_1,95 \mathrm{ng} / \mathrm{dl}\right)$ respectively with significant statistical difference ( $\mathrm{P}$ value $<0.001$ )

This is agreed with [4] On comparing the E-GST activities of the control group versus the uremic patients 
on conventional $\mathrm{HD}$, there was significant statistical difference $(\mathrm{P}<0.0001)$.

In our study The post HD analysis of E-GST level showed significant difference between control and conventional HD (p- value $0.001 \& 0.001$ ) respectively

This agreed with [7] that showed that the post HD analysis of E-GST level in Post hoc analysis showed

significant difference between control and both conventional and HDF patients $(\mathrm{P}<0.0001,0.0001)$ respectively while no significant differences between conventional HD and HDF patients $\mathrm{P}$ value $(0.061)$ were observed.

This disagreed with [4] who demonstrate significant difference in E-GST activity in control group in comparison with patients on conventional HD respectively $(\mathrm{P}$-value $=0.003)$.

This returns to [4] study showed significant statistical differences as regard markers of hemodialysis adequacy (pre-dialysis BUN\& $\mathrm{Kt} / \mathrm{V}$ ) in conventional HD that was reflected on EGST activity.

In our study there was no significant statistical difference in patients on regular haemodyalysis as regard markers of hemodialysis adequacy (URR\& Kt/V) (P value $>0.001$ ) that was also reflected on EGST level

This means that E-GST has the same power to express dialysis adequacy like URR, Kt/V Urea, Also it is mirror of URR \& $\mathrm{Kt} / \mathrm{V}$.

Our study showed that Erythrocyte glutathione transferase cut off value in HD patients $39,1 \mathrm{ng} / \mathrm{dl}$, its sensitivity was $81 \%$, specificity was $88,9 \%$ and accuracy was $84 \%$

The patients were redistributed according to $\mathrm{Kt} / \mathrm{V}$ into 2 groups: Adequate dialysis group $(\mathrm{Kt} / \mathrm{V}>1.3) \&$ Inadequate dialysis group $(\mathrm{Kt} / \mathrm{V} \leq 1.3)$

In our study patients with inadequate dialysis $(\mathrm{Kt} / \mathrm{V}$ $\leq 1.3$ ) have significantly lower URR, higher Urea 1 and higher E-GST (Mean \pm SD $(51,90 \pm 15,23) \%,(163 \pm 52,53)$ $\mathrm{mg} / \mathrm{dl},(57,02 \pm 3,28 \mathrm{ng} / \mathrm{ml})$ respectively in comparison with adequate dialysis patients $(\mathrm{Kt} / \mathrm{V}>1.3)($ Mean $\pm \mathrm{SD})$ $(77,68 \pm 4,54) \%,(128,33 \pm 30,57) \mathrm{mg} / \mathrm{dl},(42,97 \pm 6,45)$ $\mathrm{ng} / \mathrm{ml}$ ) respectively ( $\mathrm{p}$ value $<0,001,0,08,<0,001$ ) respectively

This means that E-GST can differentiate either patients receive adequate hemodialysis or not, it is like urea 2,URR and $\mathrm{Kt} / \mathrm{V}$.

That agreed with (7)who showed that Serum e-GST can predict inadequate dialysis at cut off value $>14 \mathrm{ng} / \mathrm{ml}$ with area under curve (AUC) 0.871, sensitivity 95\%, specificity $60 \%$, PP.V $70.4 \%$ and NPV $92.3 \%$. The marker e-Gst was significantly high in patients on conventional HD and HDF (mean_SD 18.35_5.61, 15.20_4.40) respectively compared with control subjects (mean_SD 2.80_1.36) P value <0.0001.

That is agreed with [11] who showed that The level of E-GST was significantly higher in patients on hemodialysis in comparison to the control group ( $\mathrm{P}$ value $<0.05)$, also E-GST levels in the inadequate hemodialysis group $(\mathrm{Kt} / \mathrm{V} \leq 1.3)$ was significantly higher than in the adequate hemodialysis group $(\mathrm{Kt} / \mathrm{V}>1.3)$
$($ Mean \pm SD $(38.19 \pm 4.52) \mathrm{ng} / \mathrm{ml},(20.32 \pm 3.78) \mathrm{ng} / \mathrm{ml})$ respectively $(\mathrm{P}$-value $<0.05)$.

This is inconsistent with (4) who divided all uremic patients using a Cut off 1.3 for $\mathrm{Kt} / \mathrm{V}$ urea into two subgroups patients with $\mathrm{Kt} / \mathrm{V} \leq 1.3 \&$ patients with $\mathrm{Kt} / \mathrm{V}$ $>1.3$, he found no significant statistical difference between both groups as regard E-GST activity $(9.7 \pm 0.7$ $\mathrm{U} / \mathrm{gHb}, 8.7 \pm 0.4 \mathrm{U} / \mathrm{gHb}$ ) respectively (P value $=0.156)$.

In our study the prevalence of E-GST level in inadequate dialysis group (Kt/V $\leq 1.3$ ) was $64 \%$ (16 patients) while in group receiving adequate dialysis $(\mathrm{Kt} / \mathrm{V}>1.3)$ prevalence was $36 \%(9$ patients)(p_value 0,002)

That is agreed with [11] who showed that E-GST level in the inadequate hemodialysis group $(\mathrm{Kt} / \mathrm{V} \leq 1.3)$ was significantly higher than in the adequate hemodialysis group $(\mathrm{Kt} / \mathrm{V}>1.3)(\mathrm{P}-$ value $<0.05)$.

In our study hemodialysis patients who have elevated E-GST level have higher risk to have inadequate dialysis than negative ones

In our study cut off point of E-GST to detect inadequate dialysis $(\mathrm{Kt} / \mathrm{V} \leq 1.3)$ is $>39,1 \mathrm{ng} / \mathrm{dl}$ with $81,3 \%$ sensitivity, $88,9 \%$ specificity and area under curve (AUC) 0.872

No available study assess E-GST level, cut off point, sensitivity and specificity to detect inadequate dialysis to compare with.

In our study there were significant negative correlation between E-GST level and URR \& Kt/V values in conventional HD patients (p-value $<0.001$, $<0.001)$ respectively

This is inconsistent with [4] who did not find correlation between E-GST activity and $\mathrm{Kt} / \mathrm{V}$ in all uremic patients on conventional HD $(\mathrm{r}=0.0378$, $\mathrm{P}=0.05)$.

E-GST pre showed significant negative correlation with Create. Pre(1), URR,KT/V ( P value 0,012, <0,001 $,<0,001)$ respectively and showed no significance with urea pre(1) (p value 0,22 )

This is in consistent with (4) who found significant positive correlation between E-GST activity and Urea 1 in all uremic patients $(\mathrm{r}=0.1906, \mathrm{P}<0.001)$.

In regular haemodyalysis , E-GST showed significant negative correlation with Create.post(2), urea $\operatorname{post}(2), \mathrm{URR}, \mathrm{KT} / \mathrm{v}$ (p value $0,013,0,003,<0,0001,<$ 0,001 respectively)

This is in consistent with (4) who found significant positive correlation between E-GST activity and Urea 2 in all uremic patients ( $\mathrm{P}$ value 0.003).

In our study we found positive correlation between EGST and both serum creatinine and urea ( $p$ value 0,013 , 0,003 respictively)

This is agreed with [12], there was positive correlation between E-GST activity and progression of CKD in four stages 1,2,3,4 according to "KDIGO" classification, the activity was $(7.4 \pm 0.5,8 \pm 1,9.5 \pm 0.6$, $12 \pm 1 \mathrm{U} / \mathrm{gHb}$ ) respectively. 


\section{References}

[1] U. Buoncristiani, F. Galli, S . Benedetti, Dramatic improvement of uremic anemia over a6-month treatment with protein-leaking dialysers. J Am Soc Nephrol, Vol.11, PP. 259, 2000.

[2] D. Sheehan, G. Meade, V.M. Foley, Structure, function and evolution of glutathione transferases: Implications for classification of non-mammalian members of an ancient enzyme superfamily. Biochem. J, Vol.360, PP.1-16, 2001.

[3] A. Bocedi, A. Noce, G. Marrone, Glutathione Transferase P1-1 an Enzyme Useful in Biomedicine and as Biomarker in Clinical Practice and in Environmental Pollution. Nutrients, Vol.11(8), PP. 1741, 2019.

[4] A. Noce, M. Ferrannini, R. Fabrini, Erythrocyte glutathione transferase: a new biomarker for hemodialysis adequacy, overcoming the $\mathrm{Kt} / \mathrm{V}$ (urea) dogma?. Cell Death \& Disease,Vol.3, PP. 377,2012.

[5] R.A. Rodriguez, J.R. Hotchkiss, A.M. O'Hare, Geographic information systems and chronic kidney disease: racial disparities, rural residence and forecasting. J Nephrol, Vol.26(1), PP. 3-15, 2013.

[6] C. Basile, L. Vernaglione, C. Lomonte, Comparison of alternative methods for scaling dialysis dose. Nephrol Dial Transplant, Vol.6(6), PP. 1232-1239, 2012.
[7] G. Abdelazim, , Erythrocyte Glutathione Transferase A Promising Marker For Hemodialysis Adequacy Kidney International Reports, Vol. 5, PP. S1S392,2020.

[8] F. Locatelli, C. Manzoni, A. Cavalli, Can convective therapies improve dialysis outcomes? Curr Opin Nephrol Hypertens, Vol.18, PP. 476-480,2009.

[9] A. Bocedi, A. Noce , R .Valentina, Erythrocyte glutathione transferase in kidney transplantation: a probe for kidney detoxification efficiency. Cell Death Dis,Vol.9(3), PP.. 288,2018.

[10] V. Panichi , A. Scatena, A. Rosati, High-volume online haemodiafiltration improves erythropoiesisstimulating agent (ESA) resistance in comparison with low-flux bicarbonate dialysis: results of the REDERT study. Nephrol Dial Transplant, Vol.30, PP. 682-689,2015.

[11]Rui Yin, Hui Qiu, Huaiyun Zuo, Detection and adequacy evaluation of erythrocyte glutathione transferase on levels of circulating toxins in hemodialysis patients, Artificial Cells, Nanomedicine , and Biotechnology, vol.44, PP. 1228-1231,2018.

[12]M. Dessì, A. Noce, K.F. Dawood, Erythrocyte glutathione transferase: A potential new biomarker in chronic kidney diseases which correlates with plasma homocysteine. Amino Acids, Vol.43, PP. 347-354,2012. 